\title{
A Critical Review of Constraint-Induced Movement Therapy and Forced Use in Children with Hemiplegia
}

\author{
Jeanne Charles ${ }^{1}$ and Andrew M. Gordon ${ }^{1,2}$ \\ ${ }^{1}$ Department of Biobehavioral Sciences, Teachers College, Columbia University, 525 West 120th Street, \\ New York, NY 10027, USA; ${ }^{2}$ Department of Rehabilitation Medicine, College of Physicians and Surgeons, \\ Columbia University, 630 West $168^{\text {th }}$ Street, New York, NY 10032, USA
}

\begin{abstract}
Hemiplegia is a physical impairment that can occur in childhood following head trauma, cerebral vascular accident or transient ischemic attack (stroke), brain tumor, or congenital or perinatal injury. One of the most disabling symptoms of hemiplegia is unilaterally impaired hand and arm function. Sensory and motor impairments in children with hemiplegia compromise movement efficiency. Such children often tend not to use the affected extremity, which may further exacerbate the impairments, resulting in a developmentally learned non-use of the involved upper extremity, termed 'developmental disuse'. Recent studies suggest that children with hemiplegia benefit from intensive practice. Forced use and Constraint-Induced Movement Therapy (CI therapy) are recent therapeutic interventions involving the restraint of the non-involved upper extremity and intensive practice with the involved upper extremity. These approaches were designed for adults with
\end{abstract}

Reprint requests to: Andrew M. Gordon, Ph.D., Department of Biobehavioral Sciences, Box 199, Teachers College, Columbia University, 525 West 120th Streei, New York, NY 10027, USA; e-mail: ag275@columbia.edu

Supported by NIH grant HD 40961 from the National Center for Medical Rehabilitation Research (National Institute of Child Health and Human Development) hemiplegia, and increasing evidence suggests that they are efficacious in this population. Recently, forced use and constraint-induced therapy have been applied to children with hemiplegia. In this review, we provide a brief description of forced use and CI therapy and their historical basis, provide a summary of studies of these interventions in children, and discuss a number of important theoretical considerations, as well as implications for postural control. We will show that whereas the studies to date suggest that both forced use and CI therapy appear to be promising for improving hand function in children with hemiplegia, the data are limited. Substantially more work must be performed before this approach can be advocated for general clinical use.

\section{KEYWORDS}

pediatric constraint-induced movement therapy, forced use, hemiplegia, cerebral palsy, traumatic brain injury, rehabilitation, children

\section{INTRODUCTION}

Hemiplegia is a physical impairment that can occur in childhood following head trauma, cerebral vascular accident or transient ischemic attack (stroke), brain tumor or congenital or perinatal 
injury (CHASA, 2003). One of the most disabling symptoms of hemiplegia is unilaterally impaired hand and arm function, which affects self-care activities such as feeding, dressing, and grooming. The impairment of the hand is often the result of damage to the motor cortex and corticospinal pathways responsible for the fine motor control of the fingers and hand (e.g., Lawrence \& Kuypers, 1968; Muir \& Lemon, 1983; Duque et al., 2003). Thus, skilled independent finger movements do not develop typically in children with hemiplegia. During tasks that require fine manipulation, such children often use several fingers (Brown et al., 1987; Twitchell, 1958), and often show abnormal hand posturing as well as reduction in distal strength and dexterity (Brown et al., 1987). Sensory disturbances can occur as well (e.g., Tizard et al., 1954; Brown et al., 1987; Lesný, 1993; Yekutiel et al., 1994; Gordon \& Duff, 1999b), further complicating any motor impairment (cf. Moberg, 1962). Furthermore, children with hemiplegia due to cerebral palsy (CP, the most motorically studied subtype of hemiplegia) have difficulty with the timing and coordination of reaching movements (Steenbergen et al., 1998; Utley \& Sugden, 1998; Hung et al. 2004), grasping (Eliasson et al., 1991; 1992; 1995; Gordon \& Duff, 1999a; 1999b; Gordon et al., 1999; Forssberg et al., 1999; Eliasson \& Gordon, 2000; Duff \& Gordon, 2003; Gordon et al., 2003), movement planning (Steenbergen et al., 1998; Steenbergen \& van der Kamp, 2004), and a deficient capacity to modulate postural adjustments during reaching (Hadders-Algra et al., 1999).

The resulting sensory and motor impairments in children with hemiplegia compromise movement efficiency. Such children often tend not to use the affected extremity, resulting in a developmentally learned non-use of the involved upper extremity that can be termed 'developmental disuse'. Typically, rehabilitation techniques have focused on teaching and reinforcing compensatory strategies that encourage use of the non-involved upper extremity to decrease functional limitations. Strong evidence for the successful application of any therapeutic approach is lacking (Boyd et al., 2001).

Recent evidence suggests that children with hemiplegic CP can improve motor performance if provided sufficient practice (Gordon \& Duff, 1999a, Boyd et al., 2001; Duff \& Gordon, 2003; Shumway-Cook et al., 2003). This finding indicates that intensive practice may improve function in the involved upper extremity that could lead to increased use in daily life. Forced use and Constraint-Induced Movement Therapy (CI therapy) are recent therapeutic interventions for individuals with hemiplegia that involve restraint of the non-involved upper extremity and intensive practice with the involved upper extremity. Increasing evidence indicates that these interventions are effective in reducing motor deficits in the involved upper extremity and increasing functional independence in adults with hemiplegia resulting from stroke (e.g., see Wolf et al., 2002 for review). Recently, forced use and constraint-induced therapy have been applied to children with hemiplegia, with moderate success. More than half the studies to date are case studies, however, and most of those remaining are smallscale studies. In addition, the types of restraint, the length of the restraint time, and the practice regimen used during the intervention varied from study to study. The purpose of the present review is to provide a brief description of forced use and $\mathrm{CI}$ therapy and their historical basis, to provide a summary of studies of such interventions in children, and to discuss a number of important theoretical considerations.

\section{HISTORICAL BASIS OF CONSTRAINT- INDUCED THERAPY}

\section{Origins of CI Therapy}

Both CI therapy and forced use are based on earlier primate unilateral deafferentation studies (e.g., Tower 1940; see Taub, 1980). Monkeys were 
observed not to use the deafferented limb unless the intact limb was restrained, and they practiced tasks using the involved limb for 1 to 2 weeks. The animals were also observed using the deafferented limb if movement of the limb was encouraged via shaping, a behavioral training technique in which a desired motor behavior is approached in small steps by successive approximations (Taub \& Wolf, 1997; cf. Skinner, 1968; Morgan, 1974; Panyan, 1980). As these monkeys regained functional use of the deafferented limb following restraint or shaping techniques, lack of use of the involved limb was considered a result of initial unsuccessful attempts to use it. Taub defined this behavior as "learned non-use" and proposed that restraint of the intact limb or use of shaping techniques would overcome the learned non-use and lead to increased "real-life" function in the involved limb (Taub, 1980). Further studies with deafferented monkeys were conducted to delineate the learned non-use and forced use paradigms (Taub et al., 1980; Taub et al., 1994). Constraint of the less affected upper extremity of monkeys deafferented in utero and at birth also shows increased use of the deafferented extremity (Taub et al., 1975), suggesting that learned non-use can be prevented if the constraint is applied early during development.

\section{Constraint-induced therapy in adults}

Two early studies in adults with hemiplegia examined the effects of forced use on the involved upper extremity (Ostendorf \& Wolf, 1981; Wolf et al., 1989). Subsequent studies involving adults following stroke utilized restraint in addition to the shaping technique as a clinical intervention to examine changes in involved upper-extremity function (e.g., Taub et al., 1993; Taub \& Wolf, 1997). Gradually the intervention was refined and eventually termed "constraint-induced movement therapy" (Taub et al., 1999).

Forced use and $\mathrm{CI}$ therapy involve restraint and practice using the involved upper extremity.
As shown in Fig. 1, although restraint is common to both techniques, the types of practice provided during the restraint period are different. By definition, placing a restraint on the non-involved upper extremity would result in practice of the involved hand and arm for any movement performed. The practice is unstructured, and the intensity of the practice is dependent on the individual wearing the restraint.

Constraint-induced therapy, however, involves a structured practice period (typically 6 hours in duration) that includes shaping and repetitive task practice (see Winstein et al., 2003). Shaping is a behavioral technique, similar to adaptive or part practice in the motor learning literature (Mane et al., 1989; Winstein, 1991; Schmidt \& Lee, 1999), in which a motor objective is approached in small steps through successive approximation, and/or the task is made more difficult or speed of the performance is increased progressively. Feedback about performance is provided on every trial. Repetitive task practice involves functional tasks that are performed continuously over a specific period, and overall feedback is provided at the end of the task (Winstein et al., 2003).

Subsequent studies of $\mathrm{CI}$ therapy examined the efficacy of this intervention for improving involved upper extremity use with different types of restraint, different types of intervention, different outcome measures, and in people with chronic, acute, and sub-acute stroke (for review Wolf et al., 2002). Neuroimaging and transcranial magnetic stimulation studies of the brain prior to and after CI therapy have demonstrated differences in cortical organization around the infarct site after the intervention. These differences led to hypotheses regarding central nervous system (CNS) plasticity and the role of $\mathrm{CI}$ therapy in cortical reorganization (Liepert et al., 1998; 2000; Levy et al., 2000; Schaechter et al., 2002; Park et al., 2004). Overall, the results of these adult studies suggest that following stroke, CI therapy and forced use may be able to improve upper extremity function 


\section{Forced Use}

Restraint

$$
\downarrow
$$

\section{Unstructured Practice}

\section{Constraint-Induced Therapy}

Restraint

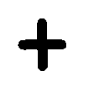

Structured Practice

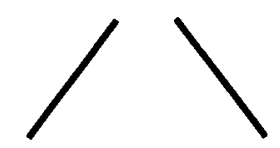

Shaping

Repetitive Practice

Fig. 1: Restraint therapies: forced use and constraint-induced movement therapy. Forced Use involves a restraint that results in unstructured practice whenever an activity is performed with the involved hand. Constraint-Induced Therapy involves a restraint and structured practice, which includes shaping and repetitive task practice. In Modified Constraint-induced therapy, structured practice may be provided that does not include the shaping and repetitive task practice.

(see Wolf et al., 2002 for review). Currently, a national randomized clinical trial with uniform $\mathrm{CI}$ therapy intervention methods and measurement protocols is being conducted at seven testing sites in the United States to test the efficacy of this intervention on a large sample size (Winstein et al., 2003).

\section{CONSTRAINT-INDUCED THERAPY/FORCED USE IN CHILDREN}

\section{Overview of studies}

It has been suggested that children with hemiplegia may also benefit from $\mathrm{CI}$ therapy/forced use, and that increased plasticity present in the developing nervous system may result in an even a better outcome (Taub \& Crago, 1995). The results of the primate studies performed in utero and shortly after birth (Taub et al., 1975) suggest that CI therapy would be effective for children with hemiplegia. Although in theory this may be the case, the restrictive nature of the constraint $(90 \%$ of waking hours) and the intensity of the structured training (i.e., shaping and repetitive task practice during a six hour program) used for adults may be too intrusive for children. In order to make the intervention child-friendly, both structured-practice tasks and the type of constraint must be adapted to suit children (see Gordon et al., 2005). 
Fifteen st udies have been conducted to date examining the efficacy of either forced use or CI therapy in the pediatric population (Table 1). The restraint used on the non-involved hand and arm in these studies included casts, slings, and mitts and the length of the intervention ranged from two to three weeks (Table 1). Eight of these have been case studies involving children with diagnoses of hemiplegic $\mathrm{CP}$, acquired brain injury, and quadricplegic CP. In addition, five of the eight studies used either forced use (constraint with unstructured practice) or modified CI therapy (constraint with semi-structured practice not involving shaping) (Yasukawa et al., 1990; Crocker et al., 1997; Charles et al., 2001; Glover et al., 2002; Pierce et al., 2002). Three of the eight studies reported using shaping techniques during the intervention (Sterr et al., 2002; Karman et al., 2003; DeLuca et al., 2003).

Seven of the 15 studies to date involved larger groups of children (Willis et al., 2002; Eliasson et al., 2003; and Taub et al., 2004; Eliasson et al., 2005; Naylor \& Bower, in press; Charles et al., unpublished; Gordon et al., unpublished). One of these studies involved forced use of the involved upper extremity during the restraint period (Willis et al., 2002) and three studies (Taub et al., 2004; Charles et al., unpublished; Gordon et al., unpublished) engaged children in structured practice during the restraint period. While various outcome measures were used to determine changes in involved upper extremity function (see Table 1), all of these studies reported increased use and function of the involved upper extremity following the intervention.

Based on the positive results of all these studies, CI therapy and forced use seem to show promise as interventions to improve involved hand and arm function in children with hemiplegia. Nevertheless, the number of children that have been involved in these studies is limited and only four studies used a randomized design. Table 2 shows the levels of evidence classification according to the American Academy of Cerebral
Palsy and Developmental Medicine (AACPDM, Evidence Report, based on Sackett, 1989). The levels represent the general strength of the evidence, with level I being the most scientifically rigorous, level II somewhat more tentative, levels III and IV even less persuasive and level V, where no conclusions can be drawn. Since none of the 15 studies of CI therapy and forced use in children are large-scale randomized clinical trials, none can readily be designated level $I$. Four of the studies fall between levels I and II (Willis et al., 2002 Taub et al., 2004; Eliasson et al., 2005; Charles et al. unpublished), whereas the remainder fall between levels III to V. Thus, the evidence to date is tentative at best. The variability in the type of restraint, the restraint duration, the length of the intervention, the intensity of practice, and evaluation measures further weaken the evidence and make it difficult to draw conclusions about efficacy and dosage. A number of issues regarding use of $\mathrm{Cl}$ therapy in pediatric populations have been raised by these studies.

\section{Inclusion criteria}

All the participants in these studies had hemiplegia, although the causes included cerebral palsy, acquired head injury, stroke, and cerebral malformations (one child's impairment was designated as quadriplegia, although one upper extremity was used more than the other (DeLuca et al., 2003). Thus, across these studies, the distribution of impairment was important but the etiology was not seen as an indicator of the appropriateness of the intervention. Only one study designated the length of time that a child exhibited hemiplegia as an inclusion criteria, i.e., chronic vs. acute (Willis et al., 2002). In addition, sensory integrity and/or amount of active movement in the involved wrist and hand were used to determine suitability for participation for children in six of the studies (Yasukawa et al., 1990; Crocker et al., 1997; Charles et al., 2001; Eliasson et al., 2003; 
TABLE 1

Summary of Pediatric Constraint-induced Therapy and Forced Use Studies

\begin{tabular}{|c|c|c|c|c|c|c|c|}
\hline Year & Author & Participants & $\mathbf{N}$ & Ages & Intervention & Testing Schedule & Outcome measures \\
\hline 1990 & Yasukawa & $\begin{array}{l}\text { Hemiplegia } \\
\text { (CP) }\end{array}$ & 1 & $15 \mathrm{~m}$ & $\begin{array}{l}4 \text { wk cast period (non- } \\
\text { involved UE) + } \\
\text { Occupational Therapy } \\
(2 \mathrm{~h} \text { 1x/wk)** }\end{array}$ & $\begin{array}{l}\text { Pre and post each } \\
\text { casting phase \& } \\
1.5 \text { y follow-up }\end{array}$ & $\begin{array}{l}\text { Occupational Therapy } \\
\text { Assessment }\end{array}$ \\
\hline 1997 & $\begin{array}{l}\text { Crocker } \\
\text { et al. }\end{array}$ & $C P^{*}$ & 1 & $2 y$ & $\begin{array}{l}3 \text { wk resting splint and } \\
\text { usual therapy } \\
\text { schedule }\end{array}$ & $\begin{array}{l}\text { During } 2 \text { wk pre } \\
\text { intervention, } \\
\text { during } 2 \text { wk. Post- } \\
\text { intervention \& } 6 \text { - } \\
\text { mo follow-up }\end{array}$ & $\begin{array}{l}\text { Structured videotape, } \\
\text { PDMS-F, \& completion } \\
\text { of daily finger feeding } \\
\text { task }\end{array}$ \\
\hline 2001 & $\begin{array}{l}\text { Charles } \\
\text { et al. }\end{array}$ & $\begin{array}{l}\text { Hemiplegia } \\
\text { (CP) }\end{array}$ & 3 & $\begin{array}{l}8- \\
13 y\end{array}$ & $\begin{array}{l}14 \text { consecutive d, } \\
6 \mathrm{~h} / \mathrm{d} \text {, sling }\end{array}$ & $\begin{array}{l}2 \times \text { pre } \\
\text { intervention, } \\
\text { immediately post- } \\
\text { intervention, } 2 \text { wk } \\
\text { and I mo post } \\
\text { intervention; 6-mo } \\
\text { follow-up }\end{array}$ & $\begin{array}{l}\text { Precision grasp force } \\
\text { coordination, J-T Test, } \\
\text { TPD, grasp strength }\end{array}$ \\
\hline 2002 & $\begin{array}{l}\text { Willis } \\
\text { et al. }\end{array}$ & $\begin{array}{l}\text { Hemiplegia } \\
\text { (stroke, CM, } \\
\text { trauma, } \\
\text { unknown } \\
\text { etiology)) }\end{array}$ & $\begin{array}{l}25 \\
T x=12 \\
\text { Cont.= } \\
13\end{array}$ & $1-8 y$ & 1 mo cast & $\begin{array}{l}\text { Pre-and } 1 \text { mo } \\
\text { post-intervention } \\
\& 6 \text {-mo follow-up }\end{array}$ & $\begin{array}{l}\text { PDMS and parent } \\
\text { interview }\end{array}$ \\
\hline 2002 & $\begin{array}{l}\text { Glover } \\
\text { et al. }\end{array}$ & $\begin{array}{l}\text { Hemiplegia } \\
\text { (CP) }\end{array}$ & 2. & $\begin{array}{l}19 \& \\
38 \mathrm{~m}\end{array}$ & $\begin{array}{l}6 \text { wk, cast for } 1 \text { st child, } \\
2 \text { PT \& OT sessions/ } \\
d \text { for } 2 \text { wk ( } w / \\
\text { shaping) and } 11 \mathrm{~d} \\
\text { splint for } 2^{\text {nd }} \text { child with } \\
2 \text { PT \& OT sessions } \\
\text { on } 9 \text { of } 11 \mathrm{~d}\end{array}$ & $\begin{array}{l}\text { Pre-and post- } \\
\text { intervention }\end{array}$ & $\begin{array}{l}\text { Clinical observation, } \\
\text { parent report, } \\
\text { videotapes during } \\
\text { therapy sessions }\end{array}$ \\
\hline 2002 & $\begin{array}{l}\text { Pierce } \\
\text { et al. }\end{array}$ & $\begin{array}{l}\text { Hemiplegia } \\
\text { (CP) }\end{array}$ & 1 & $12 y$ & $\begin{array}{l}3 \text { wk, } 1 \text { h PT/OT, } \\
4 \times / w k+\text { at-home, } \\
\text { mitt restraint }\end{array}$ & $\begin{array}{l}\text { Pre-and post- } \\
\text { intervention } \\
\text { 8-mo follow-up }\end{array}$ & WMFT, AMPS \\
\hline 2002 & $\begin{array}{l}\text { Sterr } \\
\text { et al. }\end{array}$ & $\begin{array}{l}\text { Hemiplegia } \\
\text { (stroke) }\end{array}$ & 1 & $11 y$ & $\begin{array}{l}2 \text { wk. functional } \\
\text { training, } 90 \mathrm{~min} / \mathrm{d} / \mathrm{no} \\
\text { restraint (shaping) }\end{array}$ & $\begin{array}{l}\text { Pre-and post- } \\
\text { intervention }\end{array}$ & $\begin{array}{l}\text { FAT, WMFT, MRC, } \\
\text { modified nine-hole peg } \\
\text { test, grip strength }\end{array}$ \\
\hline 2003 & $\begin{array}{l}\text { Eliasson } \\
\text { et al. }\end{array}$ & $\begin{array}{l}\text { Hemiplegia } \\
\text { (CP) }\end{array}$ & 9 & $\begin{array}{l}13- \\
18 y\end{array}$ & $\begin{array}{l}10 / 14 \mathrm{~d}, 7 \mathrm{~h} / \mathrm{d} \text {, } \\
\text { mitt-like splint, group } \\
\text { intervention }\end{array}$ & $\begin{array}{l}\text { Pre-and post- } \\
\text { intervention } \\
5 \text {-mo follow-up } \\
\text { tests }\end{array}$ & $\begin{array}{l}\text { B-OS, J-T Test, grip } \\
\text { strength, in- } \\
\text { handmanipulation, } \\
\text { Novel MotorTask } \\
\text { Performance }\end{array}$ \\
\hline
\end{tabular}


TABLE 1 (CONTINUED)

Summary of Pediatric Constraint-induced Therapy and Forced Use Studies

\begin{tabular}{|c|c|c|c|c|c|c|c|}
\hline Year & Author & Participants & $\mathbf{N}$ & Ages & Intervention & Testing Schedule & Outcome measures \\
\hline 2003 & $\begin{array}{l}\text { Karman } \\
\text { et al. }\end{array}$ & $\begin{array}{l}\text { Hemiplegia } \\
\text { (TBI, AV } \\
\text { malformation, } \\
\text { stroke) }\end{array}$ & 7 & $7-17 y$ & $\begin{array}{l}10 / 14 d, \text { Posey } \\
\text { mitt during } \\
\text { waking } h+6 h \\
\text { shaping }\end{array}$ & $\begin{array}{l}\text { Pre-and post- } \\
\text { intervention }\end{array}$ & AAUT, MAL \\
\hline 2003 & $\begin{array}{l}\text { Deluca } \\
\text { et al. }\end{array}$ & $\begin{array}{l}\text { Quadriplegia } \\
\text { (CP) }\end{array}$ & 1 & $15 \mathrm{~m}$ & $\begin{array}{l}2 \text { interventions } \\
5 \text { mo apart. } 3 \\
\text { wk, bi-valved full } \\
\text { arm cast during } \\
\text { waking hrs. } 15 \mathrm{~d} \\
\text { shaping } 6 \mathrm{~h} / \mathrm{d} \text {. }\end{array}$ & $\begin{array}{l}\text { Pre-and post- } \\
\text { intervention, daily } \\
\text { during intervention } \\
5 \text { month follow-up }\end{array}$ & $\begin{array}{l}\text { PDMS, DDST, PMAL, } \\
\text { TAUT }\end{array}$ \\
\hline 2004 & $\begin{array}{l}\text { Taub et } \\
\text { al. }\end{array}$ & $\begin{array}{l}\text { Hemiplegia } \\
\text { (CP) }\end{array}$ & $\begin{array}{l}18 \\
T x=9 \\
\text { Cont }=9\end{array}$ & $7-96 \mathrm{~m}$ & $\begin{array}{l}3 \text { wk, bi-valved } \\
\text { full-arm cast } \\
\text { during waking } \\
\text { hrs, including } 15 \\
\text { d shaping, } 6 \mathrm{~h} / \mathrm{d}\end{array}$ & $\begin{array}{l}\text { Pre- \& post-inter- } \\
\text { vention, } 3 \text { wk \& } \\
3 \text { mo post-inter- } \\
\text { vention. } 6 \text { mo } \\
\text { follow-up (Tx } \\
\text { group only) }\end{array}$ & EBS, PMAL, TAUT \\
\hline 2005 & $\begin{array}{l}\text { Eliasson } \\
\text { et al. }\end{array}$ & $\begin{array}{l}\text { Hemiplegia } \\
\text { (CP) }\end{array}$ & $\begin{array}{l}41 \\
\text { Tx. }=21 \\
\text { Cont. }=20\end{array}$ & $18 m-4 y$ & $\begin{array}{l}\text { Restraint glove } 2 \\
\text { h/d over 2-mo } \\
\text { period }\end{array}$ & $\begin{array}{l}\text { Pre- \& post- } \\
\text { intervention, } 6 \text { mo } \\
\text { follow-up }\end{array}$ & AHA \\
\hline $\begin{array}{l}\text { In } \\
\text { press }\end{array}$ & $\begin{array}{l}\text { Naylor \& } \\
\text { Bower }\end{array}$ & $\begin{array}{l}\text { Hemiplegia } \\
\text { (CP) }\end{array}$ & 9 & $\begin{array}{l}21- \\
61 \mathrm{~m}\end{array}$ & $\begin{array}{l}1 \text { h sessions } \\
2 x / \text { wk Duration }=4 \\
\text { wk. gentle } \\
\text { physical restraint } \\
+ \text { verbal } \\
\text { instruction }\end{array}$ & $\begin{array}{l}\text { Pre- \& post- } \\
\text { intervention } \\
\text { 4-wk follow-up }\end{array}$ & QUEST \\
\hline Unpubl & $\begin{array}{l}\text { Charles } \\
\text { et al. }\end{array}$ & $\begin{array}{l}\text { Hemiplegia } \\
\text { (CP) }\end{array}$ & $\begin{array}{l}22 \\
\text { Tx. }=11 \\
\text { Cont. }=11\end{array}$ & $4-8 y$ & $\begin{array}{l}10 \text { of } 12 \\
\text { consecutive } \\
\text { days, sling } 6 \mathrm{~h} / \mathrm{d}\end{array}$ & $\begin{array}{l}\text { Pre- \& post-inter- } \\
\text { vention. 1\& 6-mo } \\
\text { follow-up }\end{array}$ & $\begin{array}{l}\text { J-T Test } \\
\text { B-Os } \\
\text { CFUS }\end{array}$ \\
\hline Unpubl & $\begin{array}{l}\text { Gordon } \\
\text { et al. }\end{array}$ & $\begin{array}{l}\text { Hemiplegia } \\
\text { (CP) }\end{array}$ & $\begin{array}{l}19 \\
\text { Younger } \\
=11 \\
\text { Older=8 }\end{array}$ & $\begin{array}{l}4-8 y \\
9-14 y\end{array}$ & $\begin{array}{l}10 \text { of } 12 \\
\text { consecutive } \\
\text { days, sling } 6 \mathrm{~h} / \mathrm{d}\end{array}$ & $\begin{array}{l}\text { Pre- \& post-inter- } \\
\text { vention. } 1 \& 6 \text {-mo } \\
\text { follow-up }\end{array}$ & $\begin{array}{l}\text { J-T Test } \\
\text { B-Os } \\
\text { CFUS }\end{array}$ \\
\hline
\end{tabular}

* diagnosis not specified

* Intervention phase 2. Phases $1 \& 3$ involved UE was casted

Abbreviations: $\mathrm{CP}=$ cerebral palsy, $\mathrm{CM}=$ cerebral malformation $\mathrm{TB}=$ traumatic brain injury, $\mathrm{AV}$ malformation= arterio-venous malformation, UE=upper extremity, $T \mathrm{X} .=$ treatment, PDMS-F = Peabody Developmental Fine Motor Scales, J- $T$ Test= Jebsen-Taylor Test of Hand Function, TPD = Two-point discrimination, PDMS= Peabody Developmental Motor Scales, WMFT= Wolf Motor Function Test, AMPS= Assessment of Motor processing Skills, FAT = Frenchay Arm Test, MRC= testing for radial ulnar finger extension and wrist extension, B-Os= Bruininks-Oseretsky Test of Motor Proficiency, AAUT= Actual Amount of Use Test, MAL= Motor Activity Log, DDST= Denver Developmental Screening Test, PMAL= Pediatric Motor Activity Log, TAUT= Toddler Arm Use Test, EBS= Emerging Behavior Scale, AHA= Assiting Hand Assessment, QUEST= Quality of Upper Extremity Skills Test, CFUS= Caregiver Functional Use Survey, Cont= Control. 
TABLE 2

Levels of evidence

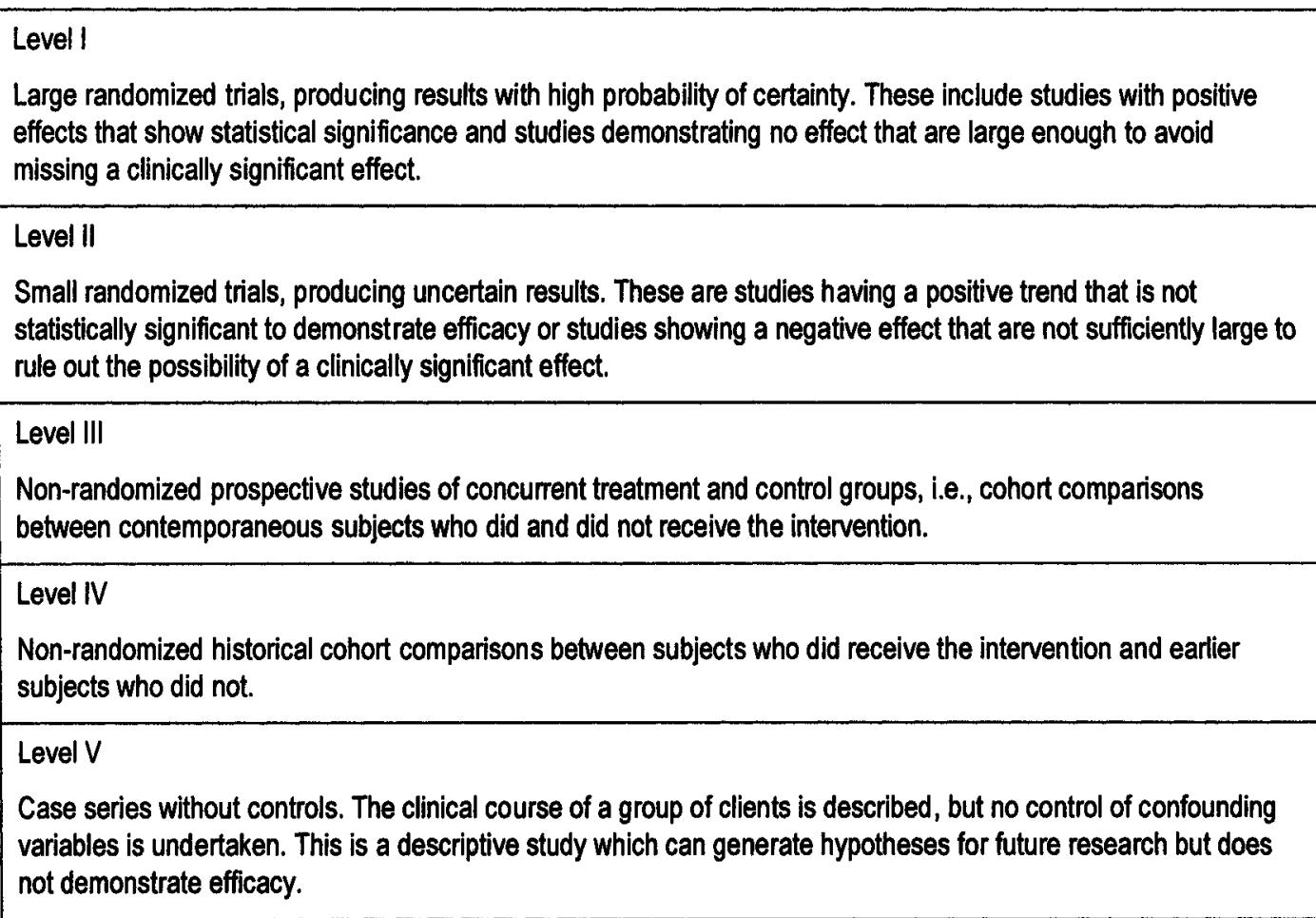

Source: American Academy for Cerebral Palsy and Developmental Medicine. Treatment Outcomes Report

Charles et al., unpublished; Gordon et al., unpublished). To date, the extent to which specific impairments, lesion timing, and the location and severity level are predictive of efficacy is not known.

\section{Age appropriateness and CNS plasticity}

The ages of the children who participated in these 15 studies ranged from 12 months to 17 years. As all of the studies reported positive results, CI therapy or forced use appears to have the potential for a range of ages that span across motor developmental levels. Nevertheless, deter- mining the optimal age for administering these interventions is not possible from these studies because the method-ologies, restraint duration, and outcome measures differed.

The types of practice and practice schedules for involved upper extremity use may also be agedependent, based on new insight into mechanisms directing motor skill acquisition. Hadders-Algra (2000) suggests that two phases of variability (primary and secondary) in motor skill development may determine the age most appropriate for new movement experiences. Primary variability, which is related to motor development during early fetal life and continues into infancy, is characterized by 
variability in movement trajectories and temporal aspects of movement and is brought through primary neural networks. The secondary variability phase begins around 2 to 3 years and persists through adolescence. During this phase, a variable movement repertoire is developed, with an efficient motor solution for specific environmental constraints. Thus, the efficacy of CI therapy intervention approaches for the pediatric population may well be dependent on age at the time of treatment, with intervention at younger ages aimed at enlarging primary neural networks through experience, and interventions conducted at older ages aimed at increasing practice of the involved extremity (Hadders-Algra, 2001).

The potentially greater CNS plasticity in children might mean that $\mathrm{CI}$ therapy and forced use can be more efficacious in younger children than in older children. Recent studies, however, have begun to define critical periods (heightened levels of plasticity) in early development, during which neuron circuits can be shaped by experience (see Hensch, 2004), that can have an impact on the selection of appropriate ages for the application of therapy. Development of the corticospinal tract subserving distal extremity control has been found to be dependent on motor activity during a key critical period in the developing kitten (e.g., Salimi $\&$ Martin, 2004). Thus, promoting early use can enhance the development of spared circuitry, optimizing developmental motor skill potential. Yet, restricting movement or motor activity during such a critical period can have the opposite effect, leading to impoverished corticospinal termination and motor behavior (e.g., Martin et al., 2004).

Although the extent to which such critical periods exist in humans is not known, corticospinal tract connections do continue to develop during the first years of life, and restricting movement of the non-involved limb for long periods could potentially have permanent repercussions for the development of motor skills in that limb. Thus, extreme caution should be exercised in restraining children at too young an age.

Although greater plasticity is generally assumed in younger children, recent findings suggest a poorer outcome of language development for children sustaining stroke under the age of 1 year than for children who sustain a stroke at a later age (Chapman et al., 2003). Thus, a general 'earlier is better rule' may not always be applicable. Furthermore, should there be greater plasticity, it may be countered by the reduced time on task that is likely achievable in young children, and because the motivation to participate in a forced use or $\mathrm{CI}$ intervention is likely to come from the parent. In contrast, adolescents may have greater motivation to improve their own motor function, given their increased awareness of their impairments and desire for social inclusion.

The stage of motor development is likely to have important implications for the type of activity practiced during the intervention. One study (Glover et al., 2002) in children with hemiplegia mentions early poverty of movement as the basis for delayed motor development and increased use of the non-involved extremity. Children with cerebral palsy can suffer from stereotypic motor behaviors resulting from the limited repertory of neuronal networks and problems in selecting the most efficient neuronal network (Hadders-Algra, 2001). Thus, $\mathrm{CI}$ therapy intervention at earlier ages may have to focus on motor development and primary motor skill acquisition rather than focusing on fine motor and manipulative skills. In addition, the type of practice that is emphasized during the intervention period must be related to a child's motor developmental age.

\section{Type of restraint}

Because the restraints in these studies are often worn for extended periods (from 6 to 24 hours per day), the type of restraint should be a consideration in adapting the intervention to children. The types of restraint was examined in several adult studies 
and included a sling, a sling combined with a resting hand splint, a half glove, a mitt, and intensive practice without a restraint. Although the type of restraint did not affect the therapeutic outcome immediately following the intervention, groups that used a half glove or intensive practice without a restraint had lower test scores 6 months after the intervention (Taub \& Wolf, 1997). The authors concluded that whereas active practice is the important variable in treatment efficacy, the type of restraint is related to the intensity of practice if the restraint is worn during all of waking hours, (Taub \& Wolf, 1997). Specifically, restraints that allow some use of the non-involved extremity will result in less intensive practice because the non-involved arm can still be used to complete tasks. Another consideration concerns safety issues when individuals are wearing the restraint in the home environment. In fact, the use of a mitt rather than a sling was ultimately employed in the national clinical trial for safety reasons, i.e., to allow the wearer to be able to use the non-involved upper extremity for protection extension in case of loss of balance or falls (Winstein et al., 2003).

The following different types of restraints were used during the restraint period in the pediatric studies: casts (Yasukawa, 1990; Glover et al., 2002; Willis et al., 2002; DeLuca et al., 2003), resting splints (Crocker, 1997; Glover et al., 2002; Eliasson et al., 2003), slings (Charles et al., 2001; Charles et al., unpublished; Gordon et al.; unpublished), mitts (Pierce et al., 2002; Karman et al., 2003), and gentle intermittent physical restraint (Naylor \& Bower, in press). Whereas each study described the extent of the restraint (usually by how much of the extremity was covered by the restraining device), few studies provided a rationale for employing a particular type of restraint. Concerns regarding compliance, safety and side-effects were stated as a consideration in the type of restraint that was used in several studies (Charles et al., 2001; Eliasson et al., 2003; Naylor
\& Bower, in press; Charles et al., unpublished; Gordon et al.; unpublished).

\section{Program intensity}

Only one study required restraint wear for the time that has been used in adult studies $(90 \%$ of waking hours) (DeLuca et al., 2003). Three studies (Willis et al., 2002; Yasukawa et al., 1990; Taub et al., 2004) required the children to don the restraint for a longer period (24-hours per day). Placing a child in a cast for either $90 \%$ or more of waking hours is restrictive because it does not give a child an opportunity during the day for successful interaction with the environment. Although compliance is assured, the frustration for children and their families could be excessive, particularly for younger children whose attention span on a task is typically short.

In the other studies, children wore restraints for shorter durations and/or the type of restraint was less restrictive. With the exception of four studies (Pierce et al., 2002; Sterr et al., 2002; Eliasson et al., 2005; Naylor \& Bower, in press), however, the restraint was never worn for less than 6 hours per day, and the intervention period was never less than 10 days (see Table 1). In this respect, the length of time of active programming and the duration of the intervention generally followed the protocol in adult $\mathrm{CI}$ therapy studies. Such variation in restraint type and duration appears to have been an effort to make the intervention more childfriendly.

The length of the intervention and the intensity of active programming are linked. A premise of CI therapy is the intensity and type of practice provided during the intervention. Based on animal deafferentation studies, Taub (1980) determined that changes in extremity motor function were transient with less than three days in a restraint. Therefore, a period of 7 to 10 days was determined to be an optimal duration for intervention. In addition, in most adult studies the time spent in active pro- 
gramming has been 6 hours/day, although the justification for this length of time has never been clearly stated (see Wolf et al., 2002 for review). Using this regimen, $\mathrm{CI}$ therapy has been shown to be effective even in older children and adolescents (Charles et al., 2001; Eliasson et al., 2003; Gordon et al. unpublished). Gains in younger children have been observed using forced use without structured practice (Willis et al., 2002) and $\mathrm{Cl}$ therapy modified to be less intense (e.g., Eliasson et al.; 2005; Naylor \& Bower, in press). Whether older children would improve with reduced intensity associated with a few hours per week or forced use without structured practice is unknown.

\section{Forced use versus $\mathrm{Cl}$ therapy}

Constraint-induced therapy with structured practice involves using the restraint of the noninvolved extremity and providing structured practice that includes both shaping and repetitive task practice (Taub \& Wolf, 1997; Wolf et al., 2002; Winstein et al., 2003). Based on this definition, any intervention that does not include shaping practice is considered either $\mathrm{Cl}$ therapy with active practice (modified CI therapy) or forced use (see Fig. 1). Although restraint of the non-involved upper extremity is common to all but two studies (Sterr et al., 2002; Naylor \& Bower, in press), structured practice that includes shaping is described in nearly half of the remaining studies (Sterr et al., 2002; Karman et al., 2003; DeLuca et al., 2003; Taub et al., 2004; Charles et al., unpublished; Gordon et al., unpublished). One study (Willis et al., 2002) clearly used forced use, and several studies included either more or longer therapy sessions to provide some more-structured practice during restraint wear (Pierce et al., 2002; Yasukawa, 1990; Crocker et al., 1997; Glover et al., 2002; Eliasson et al. 2003; 2005). Two studies (Charles et al., 2001; Eliasson et al., 2003) provided some structured practice without shaping during a 6-hour restraint period.
Constraint-induced therapy, as defined in the adult studies, involves the addition of structured practice (Fig. 1), which may not be appropriate for younger children who cannot sustain long periods of attention (Plude et al., 1994; Gordon et al., 2005). Shaping and repetitive practice provided through play activities can be made child friendly, depending on the type of activity used for structured practice but may be too difficult for children below 3 years because of time on task. Four studies that used forced use (restraint plus unstructured practice, see Fig. 1) included children 2 years of age and younger (Yasukawa, 1990; Crocker et al., 1997; Willis et al., 2002; Eliasson et al. 2003), whereas another study involving younger children (age 19 and 38 months) used modified $\mathrm{CI}$ therapy by providing an intensive therapy program that promoted hand and arm function in addition to a restraint (Glover et al., 2002). These studies support the idea that structured practice may be too difficult for younger children.

The results of one case study (DeLuca et al., 2003) specifically indicated that structured practice involving shaping was used with a child younger than 2 years. The type of activities used during the intervention, however, were based on primary motor skill acquisition, i.e., the use of the involved upper extremity in crawling rather than fine motor and manipulative skills; the duration of active practice was dependent on the child's naptime. In addition, facilitation techniques such as tapping and handover-hand assistance were used to help the children to obtain movement objectives. Although these techniques are often used in physical and/or occupational therapy, movement of the involved upper extremity may have been more passive than active, which is not indicative of the type of practice defined in the adult $\mathrm{CI}$ therapy studies.

Thus, forced use or a modified form of $\mathrm{Cl}$ therapy may be most appropriate for children 3 years of age and younger because it does not involve structured practice (shaping and repetitive task practice) and would not require the attention 
to time on task, whereas a child-friendly $\mathrm{CI}$ therapy (restraint plus structured practice, see Fig. 1) might be more appropriate for children 4 years of age and older who have the ability to sustain time on task for longer periods (Gordon et al., 2005). Nevertheless, forced use should not be viewed as less invasive because the activities in which a child chooses to engage would not be adapted to their capabilities, potentially leading to greater frustration. Accordingly, the dropout rates of participants receiving CI therapy (Gordon et al., 2005) are likely to be much lower than in those receiving forced use.

Whereas the results of these pediatric studies were positive regardless of the type of practice provided during the restraint period, the adult studies tested various types of practice during the restraint period (Taub \& Wolf, 1997). Shaping and structured task practice are based on behavioral training principles that can also be described as motor learning in terms of part-task practice (shaping), as well as practicing an entire functional task (whole practice), with changes in task constraints increasing the difficulty of the task and global feedback providing information about task performance (Winstein et al., 2003). With this in mind, motor learning principles such as practice schedules, types of task practice, types of feedback, and retention testing (Schmidt \& Lee, 1999) may be an appropriate theoretical framework to use in defining a $\mathrm{CI}$ therapy intervention that is appropriate for pediatric populations (Gordon et al., 2005). Presently the optimal ingredients for successful practice are not known.

\section{Intervention goa ls and measuring outcomes}

What outcomes can we expect from forced use and $\mathrm{Cl}$ therapy studies? Determining how to quantify changes proves difficult because most existing tests of pediatric hand function are not designed for children with unilateral impairments and all tests have limitations. We propose that assessment should take place on three levels: (1) changes in unimanual hand performance, (2) changes in bimanual hand performance, which is also impaired (e.g., Steenbergen et al., 1998; Hung et al., 2004), and (3) changes in functional outcome. Generally, quantitative outcome measures should be ageappropriate, reliable, sensitive, and repeatable. In the 15 studies to date, the outcome measures varied from study to study. Such diversity of measures can be due in part to the age range of the children (toddler to late adolescence) that were tested. Expected outcomes are linked to age. For example, most pediatric clinical measures of upper extremity function for children younger than 3 years focus on changes in motor development (at this age even functional skills are regarded as developmental). In contrast, the measures for older children focus on real-life use and advanced motor-skill acquisition.

Several studies included outcome measures that were devised specifically for the intervention (DeLuca et al., 2003; Taub et al., 2004). Standardized tests and clinical measures of hand function were also used to measure changes from pre to postintervention (see Table 1). In addition, two studies used tests that had been developed for the adult population (Pierce et al., 2002; Karman et al., 2003). Qualitative methods were used in two of the 15 studies (Crocker et al., 1997; Glover et al., 2002). Given the limitations of available tests across the age groups, additional qualitative studies can be useful to describe information about change in function.

As mentioned previously, the variability of evaluation tools among the studies makes it difficult to draw conclusions about the extent of changes following the intervention. Although the age span of the children included in the studies made it difficult to use common standardized tools, this variability could also reflect a lack of consideration for the therapeutic goals of the intervention. Based on the types of evaluation tools that were used in all of these studies, information regarding changes in development, strength, efficiency, coor- 
dination, and real-life use of involved upper extremity was evaluated (see Table 1). A clarification of inter-vention goals is important in the selection of appropriate evaluation tools. Goals and outcomes of an intervention should be consistent with the needs of the intended population (Palisano et al., 2000).

\section{Is posture in the picture?}

Upper extremity function involves appropriate postural control. At a minimum, the trunk must provide suitable support. During reaching and object manipulation, both adults (e.g., Kaminski et al., 1995; Adamovich et al., 2001; Thomas et al., 2005) and typically developing children (e.g., Van Der Fits \& Hadders-Algra, 1998; van der Heide et al., 2003) integrate trunk motion to propel the arm forward and exhibit anticipatory postural adjustments to counterbalance the destabilizing effects of limb movement. Children with hemiplegia often have an impaired capacity to modulate the postural adjustments to upper limb task-specific constraints (Hadders-Algra et al., 1999, van der Heide et al., 2004). Whether such impairments are sensitive to the intensive use of the involved extremity during forced use or $\mathrm{Cl}$ therapy is not known. For example, it is conceivable that because of the intervention, children with hemiplegia may be able to move their involved extremity more independently (less trunk contribu-tion and joint freezing). Detailed kinematic studies of reaching movements are therefore required.

By virtue of placing a restraint on one upper extremity, there can be profound effects on postural control and stability. Beyond affecting symmetry, a restraint could limit corrective responses to falls. Conversely, postural responses could be adapted to compensate for the restraint of the non-involved upper extremity. Furthermore, we have observed that when performing gross motor activities (such as throwing a ball or hitting a balloon in the air) with the involved extremity, children with hemi- plegia often have difficulty separating shoulder flexion from trunk movement. Such children require trunk stability and kinesthetic orientation to perform the task. Similarly, adults with hemiplegia improve the performance of a reaching task when the trunk is stabilized (Michealson \& Levin, 2004). We have found that initially having adults perform such activities while standing against a wall provides this input. Children instructed to try the activity generally move away from the wall after a short period of time, and their accuracy and consistency in performing these tasks improve.

\section{CONCLUSIONS}

Both forced use and CI therapy appear to be promising for improving hand function in children with hemiplegia. Both interventions involve eliciting intense practice, which is the key ingredient to improvement in motor function. Nevertheless, as most of the studies are case studies and there have yet to be any Level I studies conducted to date, substantially more work must be performed before this approach can be advocated for general clinical use. Furthermore, a number of key questions must be addressed. For example, what is the best age to administer these therapies? Would forced use be more appropriate for some ages and CI therapy more appropriate for others? Additionally, the invasive nature of such an intervention in children has to be addressed in more depth. The types of restraint and restraint times are two variables that make this type of intervention invasive for children and their families. How can we make the intervention more child-friendly while maintaining practice intensity? What is the optimal dosage response and key practice ingredients? What range of severity will likely be amenable to intervention? What are the side effects? What implications are there for postural control?

If the goal of forced use or CI therapy is to improve involved upper extremity function in 
children with hemiplegia, then the motor-learning principles of motor skill acquisition can provide a common theoretical model for developing future studies. An important consideration is that it is not the restraint that induces change, rather it is the environment that is used to solicit intensive practice. Perhaps the most important question for future work is whether similar intensive practice can be elicited without such restraint and whether this approach might result in even better functional outcome.

\section{ACKNOWLEDGMENT}

This project is supported by NIH grant HD 40961 from the National Center for Medical Rehabilitation Research (National Institute of Child Health and Human Development).

\section{REFERENCES}

Adamovich SV, Archambault PS, Ghafouri M, Levin MF, Poizner H, Feldman AG. 2001. Hand trajectory invar-iance in reaching movements involving the trunk. Exp Brain Res 138: 288-303

American Academy for Cerebral Palsy and Developmental Medicine. 1989. Treatment Outcomes Report: Evaluating research in developmental disabilities: A conceptual framework for reviewing treatment out-comes.

http://www.aacpdm.org/index?service=page/ treatmentOutcomesReport.

Boyd RN, Morris ME, Graham HK. 2001. Management of upper limb dysfunction in children with cerebral palsy: a systematic review. Eur J Neurol 8 Suppl.5: 150-166.

Brown JK, Rensburg van E, Walsh G, Lakie M, Wright GW. 1987. A neurological study of hand function of hemiplegic children. Dev Med Child Neurol 29: 287-304.

Center for Disease Control (CDC). 2000. National Center on Birth Defects and Developmental Disabilities/Frequently Asked Questions www.cdc.gov/ NCBDDDD/fag.
Chapman SB, Max JE, Gamino JF, McGlothlin JH, Cliff SN. 2003. Discourse plasticity in children after stroke: age at injury and lesion effects. Pediatr Neurol 29: 34-41.

Charles J, Lavinder G, Gordon AM. 2001. The effects of constraint induced therapy on hand function in children with hemiplegic cerebral palsy. Ped Phys Ther 13: 68-76.

CHASA. 2003. Children's Hemiplegia and Stroke Association Childhood Stroke Info www.hemikids. org.

Crocker MD, MacKay-Lyons M, McDonnell E. 1997. Forced use of the upper extremity in cerebral palsy: a single-case design. Am J Occup Ther 51: 824-833.

DeLuca SC, Echols K, Ramey SL, Taub E. 2003. Pediatric constraint-induced movement therapy for a young child with cerebral palsy: two episodes of care. Phys Ther 83: 1003-1013.

Duff SV, Gordon AM. Learning of grasp control in children with hemiplegic cerebral palsy. Dev Med Child Neurol 2003. 45: 746-757.

Duque J, Thonnard JL, Vandermeeren Y, Sebire G, Cosnard G, Olivier E. 2003. Correlation between impaired dexterity and corticospinal tract dysgenesis in congenital hemiplegia. Brain 126: 732-747.

Eliasson AC, Gordon AM; Forssberg H. Basic coordination of manipulative forces of children with cerebral palsy. Dev Med Child Neurol 1991. 33: 659-668.

Eliasson AC, Gordon AM, Forssberg H. Impaired anticipatory control of isometric forces during grasping by children with cerebral palsy. Dev Med Child Neurol 1992. 34: 216-225.

Eliasson AC, Bonnier B, Krumlinde-Sundholm L. Clinical experience of constraint induced movement therapy in adolescents with hemiplegic cerebral palsy-a day camp model. Dev Med Child Neurol 2003. 45: 357-359.

Eliasson AC, Gordon AM, Forssberg H. 1995. Tactile control of isometric fingertip forces during grasping in children with cerebral palsy. Dev Med Child Neurol 37: 72-84.

Eliasson AC, Gordon AM. Impaired force coordination during object release in children with hemiplegic cerebral palsy. Dev Med Child Neurol 2000. 42: 228-234.

Eliasson AC, Krumlinde-sundholm L, Shaw K, Wang C. 2005. Effects of constraint-induced movement therapy in young children with hemiplegic cerebral palsy: an adapted model. Dev Med Child Neurol 
47: 266-275.

Forssberg H, Eliasson AC, Redon-Zouitenn C, Mercuri E, Dubowitz L. 1999. Impaired grip-lift synergy in children with unilateral brain lesions. Brain 122: 1157-1168.

Glover JE, Mateer CA, Yoell C, Speed S. 2002. The effectiveness of constraint induced movement therapy in two young children with hemiplegia. Ped Rehab 5: $125-31$

Gordon AM, Duff SV. 1999a. Fingertip forces in children with hemiplegic cerebral palsy. I: anticipatory scaling. Dev Med Child Neurol 41: 166-175.

Gordon AM, Duff SV. 1999b. Relation between clinical measures and fine manipulative control in children with hemiplegic cerebral palsy. Dev Med Child Neurol 41: 586-591.

Gordon AM, Charles J, Duff SV. 1999. Fingertip forces during object manipulation in children with hemiplegic cerebral palsy. II: Bilateral coordination. Dev Med Child Neurol 41:176-185.

Gordon AM, Lewis S, Eliasson AC, Duff S. 2003. Object release under varying task constraints in children with hemiplegic cerebral palsy. Dev Med Child Neurol. 45: 240-248.

Gordon AM, Charles J, Wolf SL. 2005. Methods of constraint-induced movement therapy for children with hemiplegic cerebral palsy: development of a child-friendly intervention for improving upper extremity function. Arch Phys Med Rehab 86: 837-844.

Hadders-Algra M, van der Fits IB, Stremmelaar EF, Touwen BC. 1999. Development of postural adjustments during reaching in infants with $\mathrm{CP}$. Dev Med Child Neurol 41: 766-776.

Hadders-Algra $M$. The Neuronal Group Selection Theory: An attractive framework to explain variation in normal motor development Dev Med Child Neurol 2000. 42: 566-572.

Hadders-Algra M. 2001. Early brain damage and the development of motor behavior in children: clues for therapeutic intervention? Neural Plast 8: 31-49.

Hensch TK. 2004. Critical period regulation. Annu Rev Neurosci 27: 549-579.

Hung Y, Charles J Gordon AM.. 2004. Bimanual coordination during a goal-directed task in children with hemiplegic cerebral palsy. Dev Med Child Neurol 46: 746-753.

Kaminski TR, Bock C, Gentile AM. 1995. The coordination between trunk and arm motion during pointing movements. Exp Brain Res 106: 457-466.

Karman N, Maryles J, Baker RW, Simpser E, Berger-
Gross P. 2003. Constraint-induced movement therapy for hemiplegic children with acquired brain injuries. J Head Trauma Rehabil 18: 259-267.

Lawrence DG, Kuypers HGJM. 1968. The functional organization of the motor system in the monkey. I. The effects of bilateral pyramidal lesions. Brain 91: 1-14.

Lesny I, Stehlik A, Tomasek J, Tomankova A, Havlicek I. 1993. Sensory disorders in cerebral palsy: twopoint discrimination. Dev Med Child Neurol 35: 402-405.

Levy CE, Nichols DS, Schmalbrock PM, Keller P, Chakeres DW. 2001. Functional MRI evidence of cortical reorganization in upper-limb stroke hemiplegia treated with constraint-induced movement therapy. Am J Phys Med Rehabil 80: 4-12.

Liepert J, Miltner WH, Bauder H, Sommer M, Dettmers C, Taub E, Weiller C. 1998. Motor cortex plasticity during constraint-induced movement therapy in stroke patients. Neurosci Lett 250: 5-8.

Liepert J, Bauder H, Wolfgang HR, Miltner WH, Taub E, Weiller C. 2000. Treatment-induced cortical reorganization after stroke in humans. Stroke 31: 1210-1216.

Mane AM, Adams JA, Donchin E. 1989. Adaptive and part-whole training in the acquisition of complex perceptual-motor skill. Acta Psychol 1989. 71: 179-196.

Martin JH, Choy M, Pullman S, Meng Z. 2004. Corticospinal system development depends on motor experience. J Neurosci 24: 21 22-2132.

Michaelsen SM, Levin MF. 2004. Short-term effects of practice with trunk restraint on reaching movements in patients with chronic stroke: a controlled trial. Stroke 35: 1914-9

Moberg E. 1962. Criticism and study of methods for examining sensibility in the hand. Neurology 12: 819.

Morgan WG. 1974. The shaping game: a teaching technique. Behav Ther 5: 271-272.

Muir RB, Lemon RN. 1983. Corticospinal neurons with a special role in precision grip. Brain Res 261: 312316.

Naylor CE, Bower E. in press. Modified constraintinduced movement therapy for young children with hemiplegic cerebral palsy. Dev Med Child Neurol.

Ostendorf CG, Wolf SL. 1984. Effect of forced use of the upper extremity of a hemiplegic patient on changes in function. Physical Therapy 61: 1022-1027.

Palisano RJ, Campbell SK, and Harris SR. 2000. 
Decision making in pediatric physical therapy In: Campbell SK, Vander Linden DW, Palsiano RJ, eds, Physical Therapy for Children, $2^{\text {nd }} \mathrm{Ed}$. Philadelphia Pennsylvania, USA: WB Saunders Co; 198-224.

Panyan MV. 1980. How to use shaping. Lawrence, KS: $\mathrm{H} \& \mathrm{H}$ Enterprises.

Park SW, Butler AJ, Cavalheiro V, Alberts JL, Wolf SL. 2004. Changes in serial optical topography and TMS during task performance after constraintinduced movement therapy in stroke: a case study. Neurorehabil Neural Repair 18: 95-105.

Pierce SR, Daly K, Gallagher KG, Gershkoff AM, Schaumburg SW. 2002. Constraint-induced therapy for a child with hemiplegic cerebral palsy: a case report. Arch Phys Med Rehabil 83: 1462-1463.

Plude DJ, Enns JT, Brodeur D. 1994. The development of selective attention: a life-span overview. Acta Psychol (Amst) 86: 227-272.

Sackett DL. 1989. Rules of evidence and clinical recommendations on the use of antithorombotic agents. Chest 95 Suppl 2: 2-4.

Salimi I, Martin JH. 2004. Rescuing transient corticospinal terminations and promoting growth with corticospinal stimulation in kittens. $\mathrm{J}$ Neurosci 24: 4952-4961.

Schaechter JD, Kraft E, Hilliard TS, Dijkhuizen RM, Benner T, Finklestein SP, et al. 2002. Motor recovery and cortical reorganization after constraint-induced movement therapy in stroke patients: a preliminary study. Neurorehabil Neural Repair 16: 326-338.

Schmidt RA, Lee TD. 1999. Motor Control and Learning: A Behavioral Emphasis. Champagne, Illinois, USA: Human Kinetics Publishers.

Shumway-Cook A, Hutchinson S, Kartin D, Price R, Woollacott M. 2003. Effect of balance training on recovery of stability in children with cerebral palsy. Dev Med Child Neurol 45: 591-602.

Skinner BF. 1938. The Behavior of Organisms. New York, NY, USA: Appleton-Century-Croft.

Steenbergen B, Hulstijn W, Lemmins I, Meulenbroek R. 1998. The timing of prehensile movements in subjects with cerebral palsy. Dev Med Child Neurol 40: $108-114$.

Steenbergen B, van der Kamp J. 2004. Control of prehension in hemiparetic cerebral palsy: similarities and differences between the ipsi- and contralesional sides of the body. Dev Med Child Neurol 46: 325-332.

Sterr A, Freivogel S, Voss A. 2002. Exploring a repetitive training regime for upper limb hemiparesis in an in-patient setting: a report on three case studies. Brain Inj 16: 1093-1107.

Taub E. 1980. Somatosensory deafferentation research with monkeys: implications for rehabilitation medicine. In: Ince LP, ed. Behavioral Psychology in Rehabilitation medicine: Clinical Applications. Baltimore, Maryland, USA: Williams and Wilkens. 371401.

Taub E, Perrella PN, Miller EA, and Barro G. 1975. Diminution of early environmental control through perinatal and prenatal somatosensory deafferentation. Biol Psychiatry 10: 609-626.

Taub E, Harger M, Grier HC, Hodos W. 1980. Some anatomical observations following chronic dorsal rhizotomy in monkeys. Neurosci 5: 389-401.

Taub E, Miller NE, Novack TA, Cook EW, Fleming WC, Nepomuceno CS, et al. 1993. Technique to improve chronic motor deficit after stroke. Arch Phys Med Rehabil 74: 347-354.

Taub E, Crago JE, Burgio LD, Groomes TE, Cook EW $3^{\text {rd }}$, et al. 1994. An operant approach to rehabilitation medicine: overcoming learned nonuse by shaping. J Exp Anal Behav. 61: 281-293.

Taub E, Crago JE. 1995. Increasing behavioral plasticity following central nervous system damage in monkeys and man: a method with potential application to human developmental motor disability. In: Julesz B, Kovacs I, eds, Maturational Windows and Adult Cortical Plasticity. Addison-Wesley, Redwood City, California, USA: 201-213.

Taub E, Wolf SL. 1997. Constraint induction techniques to facilitate upper extremity use in stroke patients. Top Rehab Top Stroke Rehab 3: 38-61.

Taub E, Uswatte G, Pidikiti R. 1999. ConstraintInduced Movement Therapy: a new family of techniques with broad application to physical rehabilitation-a clinical review. J Rehabil Res Dev 1999. 36: 237-251.

Taub E, Ramey SL, Deluca S, Echols K. 2004. Efficacy of constraint-induced movement therapy for children with cerebral palsy with asymmetric motor impairment. Pediatrics 113: 305-312.

Thomas JS, Corcos DM, Hasan Z. 2005. Kinematic and kinetic constraints on arm, trunk, and leg segments in target-reaching movements. J Neurophysiol 93: 352-364.

Tizard JPM, Paine RS, and Crothers B. Disturbances of sensation in children with hemiplegia. JAMA 1954. 155: 628-632. 
Tower SS. 1940. Pyramidal lesions in the monkey. Brain 63: 36-90.

Twitchell TE. 1958. The grasping deficit in infantile spastic hemiparesis. Neurology 1958. 8: 13-21.

Utley A, Sugden D. 1998. Interlimb coupling in children with hemiplegic cerebral palsy during reaching and grasping at speed. Dev Med Child Neurol 40: 396-404.

Van Der Fits IB, Hadders-Algra M. 1998. The development of postural response patterns during reaching in healthy infants Neurosci Biobehav Rev 22: 521-526.

van der Heide JC, Otten B, van Eykern LA, HaddersAlgra M. 2003. Development of postural adjustments during reaching in sitting children. Exp Brain Res 151: 32-45.

van der Heide JC, Begeer C, Fock JM, Otten B, Stremmelaar E, van Eykern LA, et al. 2004. Postural control during reaching in preterm children with cerebral palsy. Dev Med Child Neurol 46: 253-266.

Willis JK, Morello A, Davie A, Rice JC, Bennett JT. 2002. Forced use treatment of childhood hemiparesis. Pediatrics 110: 94-96.

Winstein CJ. 1991. Designing practice for motor learning: clinical implications. In: Lister MJ, ed, Contemporary management of motor control problems: proceedings of the II step conference. Alexandria, Virginia. USA: Foundation for Physical Therapy.

Winstein CJ, Miller JP, Blanton S, Taub E, Uswatte G, Morris $\mathrm{D}$, et al. Methods for a multisite randomized trial to investigate the effect of constraint-induced movement therapy in improving upper extremity function among adults recovering from a cerebrovascular stroke. Neurorehab Neural Repair 2003. 17: 137-152.

Wolf SL, Lecraw DE, Barton LA, Jann BB. 1989. Forced use of hemiplegic upper extremities to reverse the effect of learned nonuse among chronic stroke and head-injured patients. Exp Neurol. 104: 125-132.

Wolf SL, Blanton S, Baer H, Breshears J, Butler AJ. 2002. Repetitive task practice: a critical review of constraint-induced movement therapy in stroke. Neurology 8:325-338.

Yasukawa A. 1990. Upper extremity casting: Adjunct treat ment for a child with cerebral palsy hemiplegia. Am J Occup Ther 1990. 44: 840-846.

Yekutiel M, Jariwala M, Stretch P. 1994. Sensory deficits in the hand of children with cerebral palsy: A new look at prevalence. Dev Med Child Neurol 1994. 36: 619-624. 

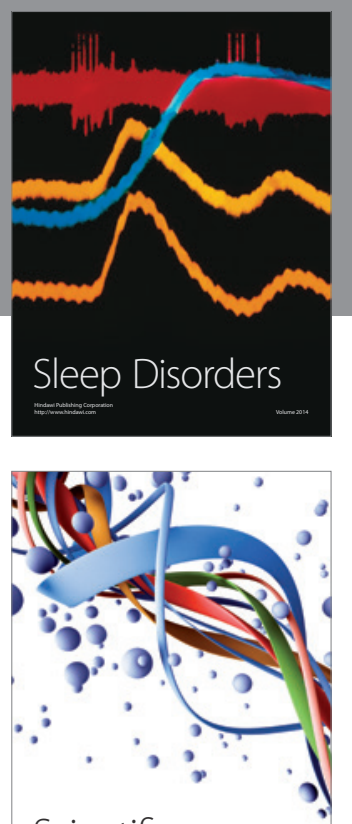

Scientifica
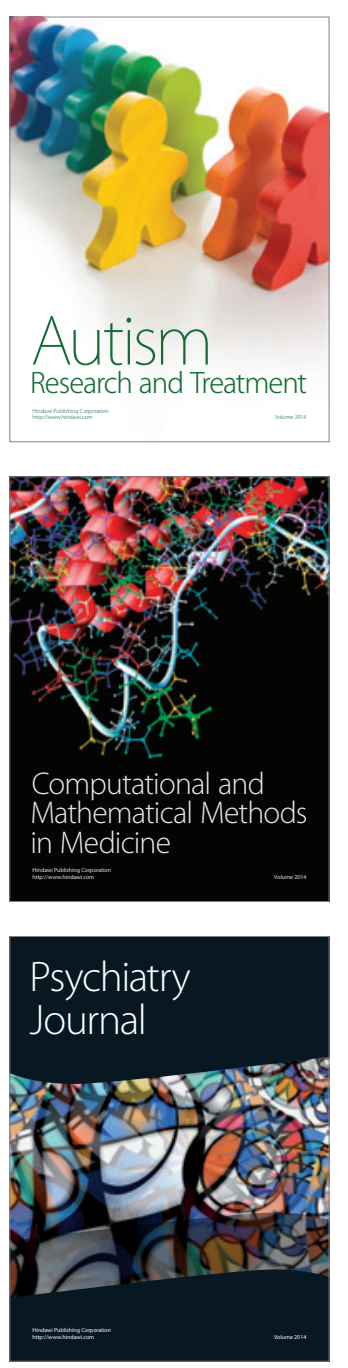
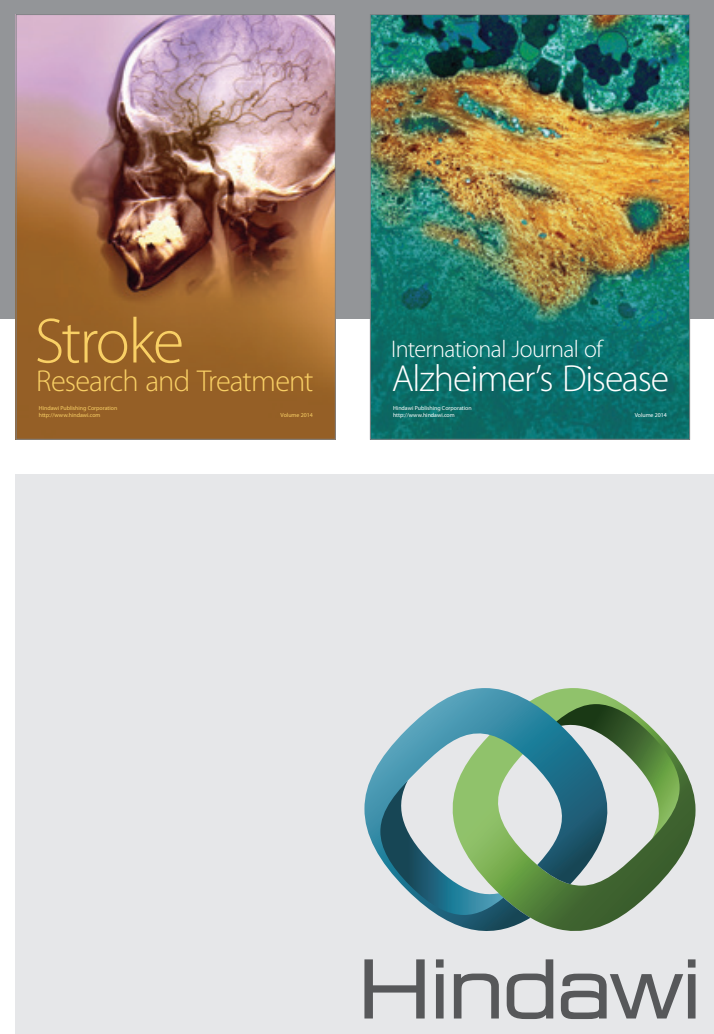

Submit your manuscripts at

http://www.hindawi.com
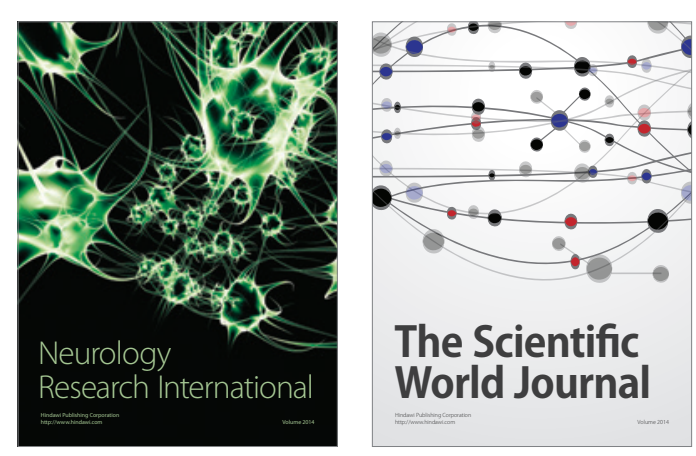

The Scientific World Journal

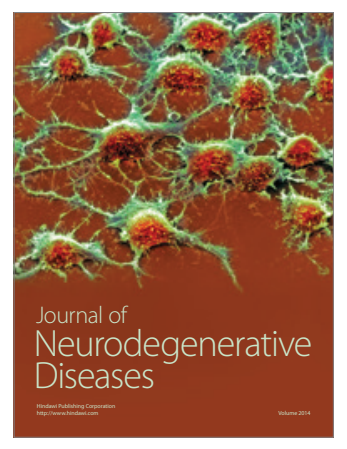

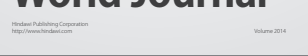

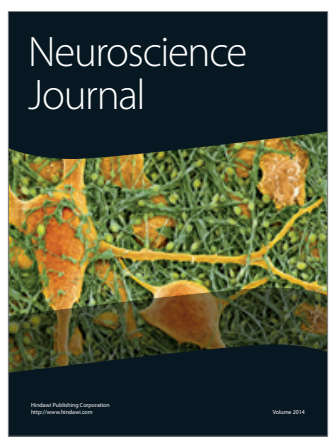

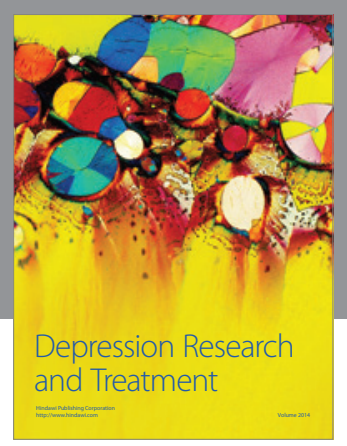
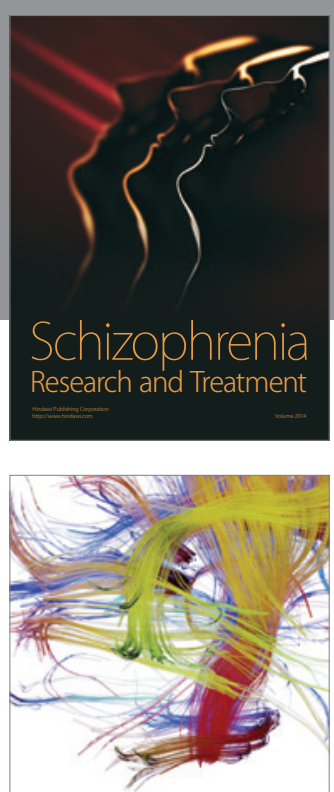

Brain Science

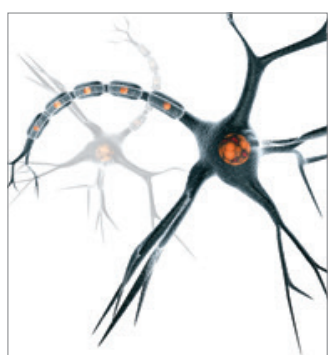

Neural Plasticity
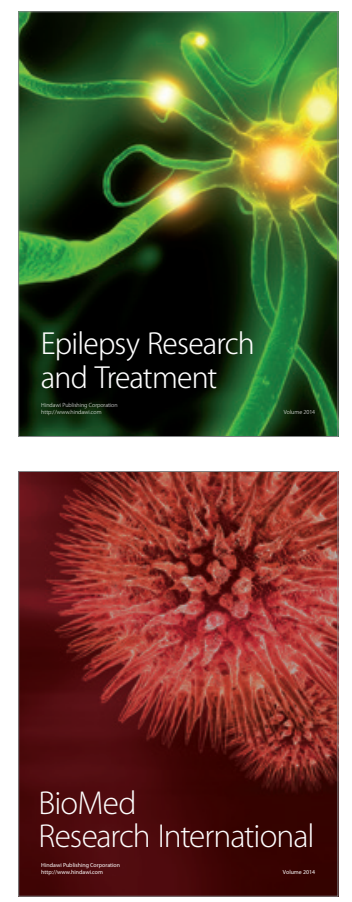

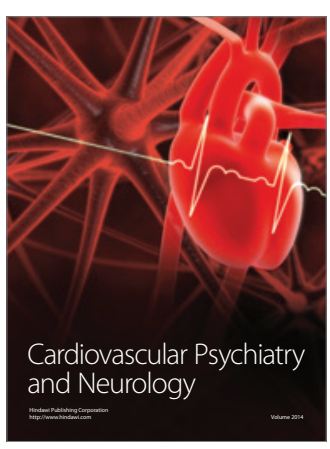

Parkinson's

Disease
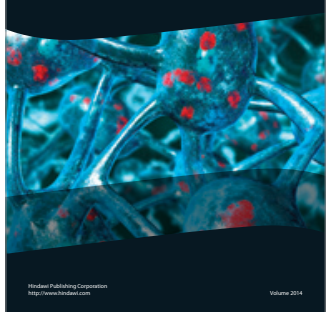